\title{
Saskatchewan medical school mulls overhaul
}

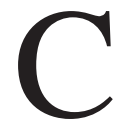

ommunity clinicians may soon provide the bulk of instruction to medical students at the University of Saskatchewan in Saskatoon as the school's College of Medicine is proposing to divide its activities into separate arms to overcome accreditation woes and a flagging performance in its current research endeavours.

The changes would alter the balance between clinical work and pedagogy for existing full-time faculty and transfer more of the teaching load onto community physicians. They'd be paid on a contractual basis and fall under the umbrella of a newly created division of clinical instruction (www.medicine .usask.ca/concept/College\%20of\%20 Medicine\%20Concept $\% 20$ Paper.pdf).

All full-time faculty would still be compelled to do a measure of teaching. Some, though, would fall under a research track, in which they would be expected to devote $50 \%-75 \%$ of their time to conducting research within a new division of clinical science. They'd spend a maximum $25 \%-50 \%$ of their time on teaching and clinical work.

The remainder of the faculty, would fall under the rubric of a division of biomedical and population science, which would include community health, epidemiology and other basic science programs. Those professors would continue to teach undergraduate and postgraduate students.

The move substantially alters the roles and responsibilities of clinical faculty members, says Dr. William Albritton, dean of the college.

Currently, too few clinical faculty members teach classes, conduct research or accept graduate students, with the majority spending "up to $90 \%$ of their time doing clinical work" on the university's dime, Albritton says. "There's constant tension between academic expectations and clinical work, and the demands of clinical service have really begun to erode the research and scholarship and teaching work of the university faculty."

The proposed changes are being dri-

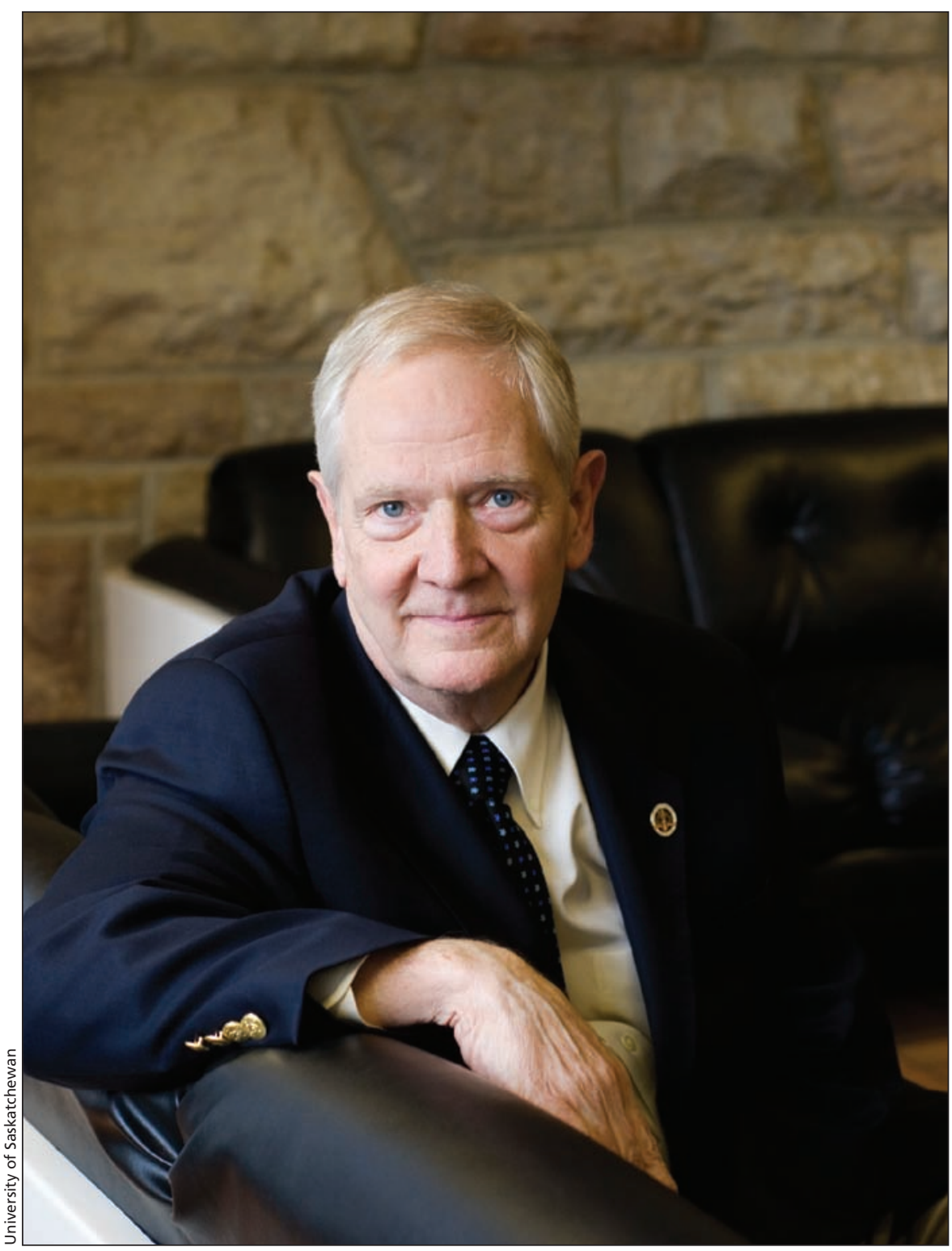

Too few clinical faculty members at the University of Saskatchewan's medical school teach classes, conduct research or accept graduate students, with the majority spending "up to $90 \%$ of their time doing clinical work" on the university's dime, says Dr. William Albritton, dean of the College of Medicine.

ven in part by failing grades that the college received from the Committee on Accreditation of Canadian Medical Schools in July 2011. The committee placed the school on warning of probation, citing the lack of a clear process for assigning educational responsibilities to, and ensuring the accountability of, full-time clinical faculty, among other areas of noncompliance (https://s3 .amazonaws.com/s3.documentcloud.org /documents/327424/2012-03-21-10-13 -06.pdf). It gave the college until March 2013 to introduce reforms or face losing its accreditation.

Pressures to bolster research output are also driving the need for change, Albritton says. "The province has 
invested almost $\$ 400$ million in building a new academic facility, and so there are expectations to improve our research."

Clinical faculty members, who are concerned they will lose their academic credentials if they fail to increase their academic workload, have responded to the proposal with "anger, frustration, and outrage."

Typical was the response from clinicians within the Department of Surgery. "I will need a great deal more information about loss of my individual tenured university faculty appointment before I am prepared to accept the simplistic approach that I will suddenly become a community based faculty member," Dr. William Dust, interim head of the department of surgery, wrote on behalf of his colleagues (www .medicine.usask.ca/concept/concept $\% 20$ reply\%20surgery.pdf).

"This is a major shake-up, and I think some people have the potential to get seriously burned," Dust added.

The Department of Medicine, meanwhile, warned that the changes could detrimentally affect patient care as clinicians who are faculty members would have to assume more teaching and research responsibilities. "The concept that non-faculty clinicians will be able to relieve the patient burden sounds fine on paper, but in reality where are these warm bodies coming from?" (www.medicine .usask.ca/concept/DoMResponseCoM Concept1May12.pdf).

Others argued that community clinicians cannot readily pick up a pedagogical shortfall. While many community clinicians "teach for love of teaching and a sense of responsibility," nonfaculty physicians cannot be expected to "undertake the significant clinical teaching load required ... when they are already struggling to meet the heavy clinical service demands in their various communities," wrote a group of 23 faculty members in the Department of Academic Family Medicine (www .medicine.usask.ca/concept/summary -of-feedback/Family\%20Medicine $\% 20$ Response\%20to\%20Concept\%20Paper. pdf). That pool has been tapped for many years, it added. "The required increased capacity implied by the realignment proposal is simply not there."

But senior university brass defend the move as crucial to the "survival" of the college's teaching and research missions.

"We can look at other universities and see that, depending on the metrics you use, our college is in the bottom couple," says Brett Fairbairn, University of Saskatchewan provost and vice-president academic. "It's not necessarily because we have fewer resources per faculty member, or that other schools that have more research than we do have worse teaching. It's because there are organizational structures that can optimize the resources they've got."

Albritton explains that the college's management structure allows many physicians who work for the university to be simultaneously working within the Saskatoon Health Region, which is responsible for regional delivery of health services. Some faculty do "insignificant amounts of teaching and research, yet we can't give them insignificant amounts of resources because they're entitled in the collective agreement to full academic salaries no matter how much they deliver," he notes.

That's not an environment conducive to protected time for research, Fairbairn says. "Someone who wishes to conduct research in a clinical setting will more than likely have to do it off the side of their desk after they've done their clinical duties equivalent to everyone else."

"Even when we've had resources and candidates for clinical research positions, we haven't always been able to complete hiring because the environment hasn't been there. It's just hard to make it work in our current structure," Fairbairn adds.

The reforms also appear to be aimed at articulating a clearer line between clinical and academic responsibilities. "Those whose predominant focus is clinical practice need to be aligned with health services and planning for service delivery; [and] those with a predominant focus in research or education need to be aligned with the university," the paper notes.

Community clinicians under the new division of clinical instruction "will not hold full-time academic appointments and will not be expected to perform fulltime academic duties including research, administration, and didactic teaching. Duties will be assigned (and accountability ensured) via the negotiation of individual service contracts," it adds.

The proposal will be submitted to the university's faculty council for approval May 17. — Lauren Vogel, CMAJ

CMAJ 2012. DOI:10.1503/cmaj.109-4206 